\title{
Role of perivascular adipose tissue in nicotine-induced endothelial cell inflammatory responses
}

\author{
CHAO-NAN WANG ${ }^{1 *}$, GEN-HUAN YANG ${ }^{1 *}$, ZHAN-QI WANG $^{1}$, CHANG-WEI LIU ${ }^{1}$, TIAN-JIA LI ${ }^{1}$, \\ ZHI-CHAO LAI ${ }^{1}$, SHI-YING MIAO ${ }^{2}$, LIN-FANG WANG ${ }^{2}$ and BAO LIU ${ }^{1}$ \\ ${ }^{1}$ Department of Vascular Surgery, Peking Union Medical College Hospital; \\ ${ }^{2}$ State Key Laboratory of Medical Molecular Biology, Institute of Basic Medical Sciences, \\ Peking Union Medical College and Chinese Academy of Medical Sciences, Beijing 100730, P.R. China
}

Received September 20, 2015; Accepted October 18, 2016

DOI: $10.3892 / \mathrm{mmr} .2016 .5934$

\begin{abstract}
Smoking is considered to be one of the primary causes of atherosclerosis and vascular injury. Previous studies have shown that nicotine in tobacco can lead to vascular inflammation and endothelial dysfunction. Perivascular adipose tissue (PVAT) is known to secrete various types of adipokines to maintain vascular homeostasis. The present study investigated whether nicotine-induced PVAT malfunction can accelerate endothelial inflammation and eventually lead to endothelial dysfunction. The levels of inflammatory adipokines, including nuclear factor $(\mathrm{NF})-\kappa \mathrm{B}$, interleukin (IL)-1 $\beta$, IL-6 and tumor necrosis factor (TNF)- $\alpha$, the ICAM-1 and VCAM-1 adhesion molecules and secretion of adiponectin were assessed in mature adipocytes and endothelial cells cultured alone or in co-culture under nicotine stimulation. It was found that nicotine reduced the secretion of adiponectin and stimulated secretion of the NF- $\kappa$ B, IL-1 $1 \beta$, IL- 6 and TNF- $\alpha$ inflammatory adipokines in mature adipocytes. Although nicotine stimulated endothelial cells to secrete IL-1 $\beta$ and IL-6, no significant increase in the secretion of TNF- $\alpha$ was observed. The co-culture of mature adipocytes with endothelial cells markedly augmented the expression of the $\mathrm{NF}-\kappa \mathrm{B}$, IL-1 $\beta$, IL- 6 and TNF- $\alpha$ inflammatory adipokines and the ICAM-1 and VCAM-1 adhesion molecules, and significantly lowered the levels of adiponectin. These findings suggested that nicotine induced mature adipocyte dysfunction, which caused the abnormal secretion of adiponectin and inflammatory adipokines, and exacerbated endothelial inflammation.
\end{abstract}

Correspondence to: Dr Bao Liu, Department of Vascular Surgery, Peking Union Medical College Hospital, Peking Union Medical College and Chinese Academy of Medical Sciences, 1 Shuaifuyuan, Wangfujing Street, Beijing 100730, P.R. China

E-mail: liubao72@aliyun.com

${ }^{*}$ Contributed equally

Key words: perivascular adipose tissue, nicotine, vascular endothelial cells, co-cultures, inflammatory response
These findings also suggested a mechanism whereby nicotine induced the secretion of adiponectin and inflammatory cytokines by adipocytes. The results of the present study elucidated a novel pathway induced by cigarette smoke, which contributed to atherosclerosis and vascular injury.

\section{Introduction}

Cigarette smoking is a major cause of premature mortality rates worldwide, and is an established risk factor for cardiovascular disease (1). Tobacco smoke contains $>4,000$ chemical components (2), which have been shown to exert marked effects on the magnitude and regulation of inflammatory responses (3-5). Compounds, including nicotine, act via various pathways to cause significant damage to endothelial cells $(6,7)$, resulting in endothelial dysfunction and a series of subsequent pathophysiological reactions, ultimately leading to atherosclerotic vascular disease. However, the mechanism linking nicotine to this vascular disease remains to be fully elucidated.

Perivascular adipose tissue (PVAT) is a major endocrine and paracrine organ producing a variety of mediator proteins, signaling proteins, known collectively as 'adipokines'. Adipocytes are the predominant cell type in adipose tissue, which secrete numerous adipokines into the blood. It has become clear that several adipokines are mediators, which form communications between adipose tissues and the vasculature $(8,9)$.

A number of adipokines are mediators, which allow for communication between adipose tissues and the vasculature. PVAT can secrete inflammatory adipokines, including tumor necrosis factor (TNF)- $\alpha$, interleukin (IL)-6 and IL-1 $\beta$, however, certain adipokines can also secrete anti-inflammatory adipokines, including adiponectin and IL-10. Adiponectin is a polypeptide and an adipose tissue-specific collagen-like factor, which is abundantly present in plasma and possesses anti-atherogenic properties. Adiponectin has been associated with cardiovascular disease (10) and hypertension (11). There is also evidence indicating that adipokines can alter endothelial function and atherogenesis. A study of the association between adiponectin concentrations and smoking habits indicated that the nicotine in tobacco smoke can reduce plasma adiponectin via inhibition of the secretion and expression of 
adiponectin in adipocytes (12). When these inflammatory adipokines are released from adipose tissue, they induce adverse effects on the vasculature (13) and induce the release of adhesion molecules by endothelial cells, thereby promoting leukocyte-endothelium interactions during the inflammatory response. These observations indicate that PVAT malfunction can further exacerbate endothelial inflammation via abnormal cytokine secretion. However, whether nicotine can cause abnormal inflammatory responses in the vessel wall through altering the endocrine and paracrine functions of PVAT, which can eventually result in increased endothelial inflammation, remains to be fully elucidated.

The present study investigated the roles of nicotine-induced secretion of inflammatory cytokines and adiponectin from adipocytes and endothelial cells, and examined the effects on interactions between adipocytes and endothelial cells. The nicotine-induced stimulated secretion of adiponectin and inflammatory adipokines by adipocytes and endothelial cells were examined. A co-culture system of adipocytes and endothelial cells was also included to examine the effects of nicotine-induced secretion of inflammatory cytokines and adiponectin on the expression of adhesion molecules. It was shown that nicotine enhanced the secretion of inflammatory cytokines and the expression of adhesion molecules in co-cultures of adipocytes and endothelial cells.

\section{Materials and methods}

Materials. Dulbecco's modified Eagle's medium (DMEM) containing high glucose and glutamine was purchased from Hyclone (GE Healthcare Life Sciences, Logan, UT, USA), and fetal bovine serum (FBS), calf serum (CS), trypsin and penicillin G-streptomycin were purchased from Gibco (Thermo Fisher Scientific, Inc., Waltham, MA, USA). Insulin, 3-isobutyl-1-methylxanthine, and dexamethasone were obtained from Sigma-Aldrich (Merck Millipore, Darmstadt, Germany). Endothelial cell medium (ECM) and endothelial cell growth supplement (ECGS) were purchased from ScienCell Research Laboratories (Carlsbad, CA, USA). The Transwell system was purchased from Corning Incorporated (Corning, NY, USA). Anti-VCAM-1 antibody was purchased from Epitomics (Burlingame, CA, USA). Anti-ICAM-1 and anti-NF- $\mathrm{kB}$ p65 were from Abcam (Cambridge, UK). The horseradish peroxidase (HRP)-conjugated secondary antibodies were from Abcam, and the enhanced chemiluminescence assay kit was from Santa Cruz Biotechnology, Inc. (Santa Cruz, CA, USA). ELISA kits for IL-1 $\beta$, IL-6, TNF- $\alpha$ and adiponectin were obtained from R\&D Systems, Inc. (Minneapolis, MN, USA). Nicotine and all other chemicals were purchased from Sigma-Aldrich (Merck Millipore).

Cell culture and treatment. Mouse 3T3-L1 preadipocytes (Cell Resource Center, Institute of Basic Medical Sciences, Chinese Academy of Medical Sciences and Peking Union Medical College, Beijing, China) were cultured in DMEM-high glucose basal medium with $10 \% \mathrm{CS}$ and antibiotics $(100 \mathrm{U} / \mathrm{ml}$ penicillin $\mathrm{G}$ and $100 \mu \mathrm{g} / \mathrm{ml}$ streptomycin) in a humidified atmosphere containing $5 \% \mathrm{CO}_{2}$ at $37^{\circ} \mathrm{C}$. The culture medium was replaced every $48 \mathrm{~h}$. To obtain fully differentiated adipocytes, on day 2 post-confluence, the cells were induced to differentiate using a standard protocol, as described previously (14). In brief, the cells were induced to differentiate by replacement of the medium to DMEM containing 10\% FBS supplemented with an adipogenic cocktail $(1 \mu \mathrm{g} / \mathrm{ml}$ insulin, $0.5 \mathrm{mM}$ isobutylmethylxanthine and $1 \mathrm{mM}$ dexamethasone). After 2 days, the medium was replaced with DMEM-high glucose medium supplemented with 10\% FBS and insulin. The culture medium was then replaced every 2 days with DMEM-high glucose with 10\% FBS medium until $>90 \%$ of cells were observed to exhibit an adipocyte phenotype when observed under a light microscope (Olympus Corporation, Tokyo, Japan).

Human umbilical vein endothelial cells (HUVECs; ScienCell Research Laboratories) were maintained in ECM and $15 \mathrm{mg} / \mathrm{l} \mathrm{ECGS}$ in an atmosphere of $5 \% \mathrm{CO}_{2}$ at $37^{\circ} \mathrm{C}$.

The standard protocol used for the mouse 3T3-L1 preadipocytes and HUVECs was similar to that described previously $(15,16)$, and the mouse $3 \mathrm{~T} 3-\mathrm{L} 1$ preadipocyte differentiation protocol was as described above. The mature adipocytes and HUVECs were co-cultured in a 6-well Transwell system with a $0.4-\mu \mathrm{m}$ porous membrane to separate the upper and lower chambers. An initial seeding density of $1 \times 10^{5}$ differentiated $3 \mathrm{~T} 3-\mathrm{L} 1$ cells per well were cultured in the lower chamber and the HUVECs density of $5 \times 10^{4}$ were cultured in the upper chamber.

The mature adipocytes and HUVECs were exposed to nicotine concentrations of $10^{-6}, 10^{-7}$ and $10^{-8} \mathrm{~mol} / \mathrm{l}$ for $24 \mathrm{~h}$, following which the supernatant and cells were collected. The culture supernatants were collected from each sample and centrifuged at $800 \mathrm{xg}$ for $5 \mathrm{~min}$ at $4^{\circ} \mathrm{C}$.

Western blot analysis. Total proteins were extracted from the mature adipocytes and HUVECs following cell lysis, the lysates were maintained at $100^{\circ} \mathrm{C}$ for $10 \mathrm{~min}$ and centrifuged at 23,200 x $g$ for $15 \mathrm{~min}$. The protein concentrations in each sample were determined using a Bicinchoninic Acid Protein Assay kit (Beyotime Institute of Biotechnology, Haimen, China) and equal quantities (20 $\mu \mathrm{g})$ were resolved using 10\% SDS-polyacrylamide gels. The proteins were transferred onto a polyvinylidene fluoride membrane (EMD Millipore, Billerica, MA, USA). The membranes were blocked in 5\% skimmed milk in TBST containing $20 \mathrm{mM}$, Tris- $\mathrm{HCl}$ (pH 7.6), $137 \mathrm{mM}$ $\mathrm{NaCl}$ and $0.05 \%$ Tween-20, for $1 \mathrm{~h}$ at room temperature. The membranes were then incubated with rabbit polyclonal antibody against VCAM-1 (1:1,000; cat. no. ab134047), rabbit polyclonal antibody against ICAM-1 (1:1,000; cat. no. ab7815), or rabbit polyclonal antibody against NF-אB p65 (1:1,000; cat. no. ab16502) overnight at $4^{\circ} \mathrm{C}$. Subsequently, the membranes were incubated with HRP-conjugated secondary antibodies (1:5,000; cat. no. ab205718) for $1 \mathrm{~h}$ at room temperature. Bands were detected using an enhanced chemiluminescence assay kit.

ELISA. The culture supernatants from the mature adipocytes, HUVECs and the co-cultured cells in the Transwell system were collected from each sample $24 \mathrm{~h}$ following the addition of nicotine, and supernatants were then centrifuged at $800 \times g$ for $5 \mathrm{~min}$ at $4^{\circ} \mathrm{C}$. The collected supernatants were aliquoted, snap frozen and stored at $-80^{\circ} \mathrm{C}$ until later use. Concentrations of IL-1 $\beta$, IL- 6 , TNF- $\alpha$, and adiponectin were assayed using 
mouse ELISA kits for IL- $1 \beta$, IL- 6 , TNF- $\alpha$ and adiponectin according to the manufacturer's protocols.

Statistical analysis. Data are expressed as the mean \pm standard error of the mean and were compared using analysis of variance. Each experiment was performed at least three times. $\mathrm{P}<0.05$ was considered to indicate a statistically significant difference. Statistical analysis was performed using SPSS 17.0 software (SPSS, Inc., Chicago, IL, USA).

\section{Results}

Effects of nicotine on the secretion of adiponectin and inflammatory adipokines in 3T3-L1 adipocytes. The present study first examined the effects of nicotine on the secretion of adipokines by 3T3-L1 adipocytes. Mature adipocytes were exposed to various concentrations of nicotine (final concentrations, $10^{-6}, 10^{-7}$ and $10^{-8} \mathrm{~mol} / \mathrm{l}$ ) for $24 \mathrm{~h}$.

Compared with the controls, the secretion of adiponectin into the culture media was significantly reduced following treatment with nicotine at concentrations of $10^{-6}, 10^{-7}$ and $10^{-8} \mathrm{~mol} / \mathrm{l}(\mathrm{P}<0.05$; Fig. 1$)$. The secretion levels of IL- $1 \beta$ and IL-6 were then examined using ELISA, and it was found that $10^{-6}$ or $10^{-7} \mathrm{~mol} / \mathrm{l}$ nicotine resulted in elevated levels of IL- $1 \beta$ and IL-6 (Fig. 2). Following treatment with $10^{-7}$ or $10^{-8} \mathrm{~mol} / 1$ nicotine, no significant difference in the secretion of TNF- $\alpha$ by mature adipocytes was observed $(\mathrm{P}>0.05)$; only at concentrations of $10^{-6} \mathrm{~mol} / \mathrm{l}$ nicotine did the levels of secreted TNF- $\alpha$ increase significantly $(\mathrm{P}<0.05)$. These findings suggested that nicotine induced a reduction in the levels of adiponectin, and increases in the levels of IL- $1 \beta$ and IL- 6 secreted by mature adipocytes.

Effects of nicotine on inflammatory cytokine secretion by HUVECs. The supernatants from HUVECs were collected at a single time point $(24 \mathrm{~h})$ and exposed to various concentrations of nicotine (final concentrations, $10^{-6}, 10^{-7}$ and $10^{-8} \mathrm{~mol} / \mathrm{l}$ ).

The levels of IL-1 $\beta$, IL- 6 and TNF- $\alpha$ were detected using ELISA. The secretion of IL- $1 \beta$ and IL- 6 by HUVECs was elevated following nicotine treatment, compared with the control cells $(\mathrm{P}<0.05)$, whereas no significant differences were observed in the secretion of TNF- $\alpha$ (Fig. 3). These findings indicated that the secretion of IL- $1 \beta$ and IL- 6 by HUVECs showed a similar trend to that of the mature adipocytes, suggesting a causative association between nicotine and the secretion of inflammatory adipokines by adipocytes and HUVECs.

Nicotine-induced expression of inflammatory adipokines, adhesion molecules and adiponectin, and their effects on adipocyte-HUVEC interactions. The co-cultured mature adipocytes and HUVECs were exposed to $10^{-6} \mathrm{~mol} / \mathrm{l}$ nicotine for $24 \mathrm{~h}$. This co-culture of the mature adipocytes and HUVECs resulted in a significant increase in the levels of IL- 6 and IL-1 $\beta$ in the supernatants $(\mathrm{P}<0.05$; Fig. 4). The levels of TNF- $\alpha$ were similar to those of the single cultures of mature adipocytes and HUVECs, but a statistically significant difference was observed $(\mathrm{P}<0.05$; Fig. 4). Furthermore, measurements of secreted adiponectin using ELISA showed that the levels in the co-culture group were significantly decreased, compared with

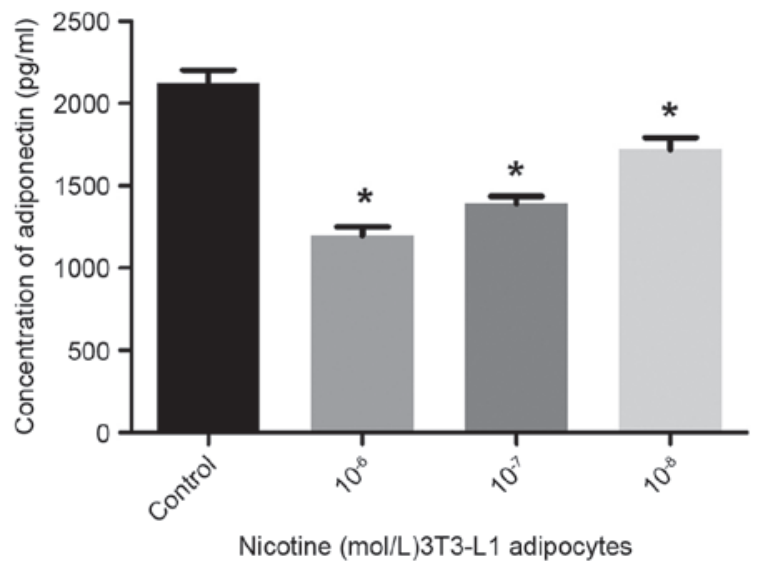

Figure 1. Nicotine reduces secretion of adiponectin. ELISA showed that, compared with the control, adiponectin secretion into the media was significantly reduced following stimulation with nicotine at concentrations of $10^{-6}$, $10^{-7}$ and $10^{-8} \mathrm{~mol} / 1 .{ }^{*} \mathrm{P}<0.05$, vs. control ( $\mathrm{n}=5$ /group).

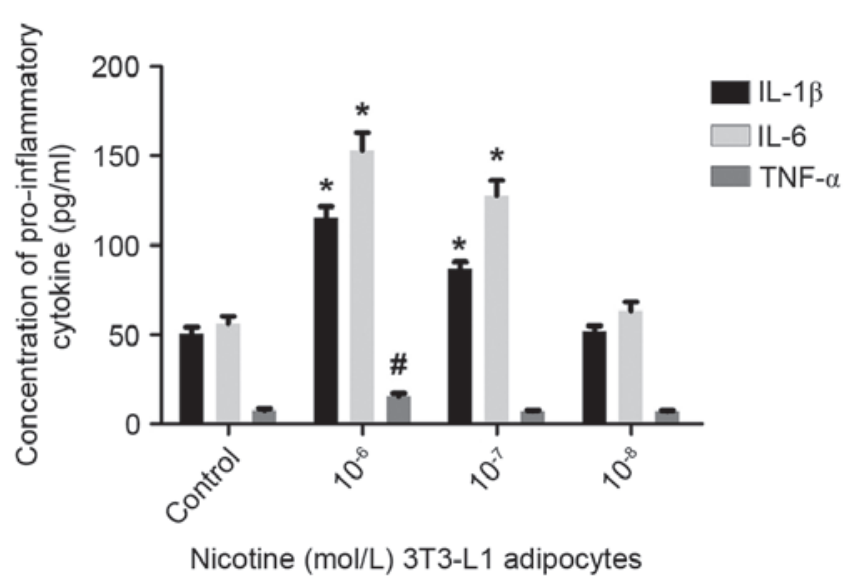

Figure 2. Effects of nicotine on the secretion of IL-1 $\beta$, IL-6 and TNF- $\alpha$ by adipocytes. ELISA showed that, compared with the control, levels of IL-1 $\beta$ and IL-6 into the media were significantly enhanced following stimulation with nicotine at concentrations of $10^{-6}$ and $10^{-7} \mathrm{~mol} / \mathrm{l}$. TNF- $\alpha$ was significantly increased with $10^{-6} \mathrm{~mol} / 1$ nicotine only. ${ }^{*} \mathrm{P}<0.05$ and ${ }^{*} \mathrm{P}<0.05$, vs. control ( $\mathrm{n}=5 /$ group). IL, interleukin; TNF- $\alpha$, tumor necrosis factor- $\alpha$.

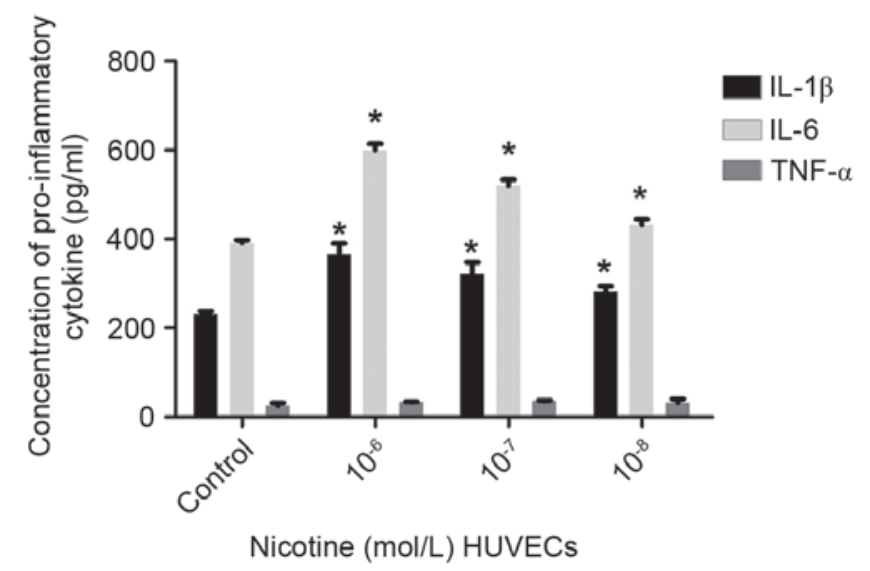

Figure 3. Effects of nicotine on the secretion of IL-1 $\beta$, IL-6 and TNF- $\alpha$ by HUVECs. ELISA showed that, compared with the control, the levels of IL-1 $\beta$ and IL-6 into the media were significantly enhanced by nicotine stimulation at concentrations of $10^{-6}, 10^{-7}$ and $10^{-8} \mathrm{~mol} / \mathrm{l}$. Levels of TNF- $\alpha$ were not altered significantly. ${ }^{*} \mathrm{P}<0.05$, vs. control ( $\mathrm{n}=5 /$ group). HUVECs, human umbilical vein endothelial cells; IL, interleukin; TNF- $\alpha$, tumor necrosis factor- $\alpha$. 


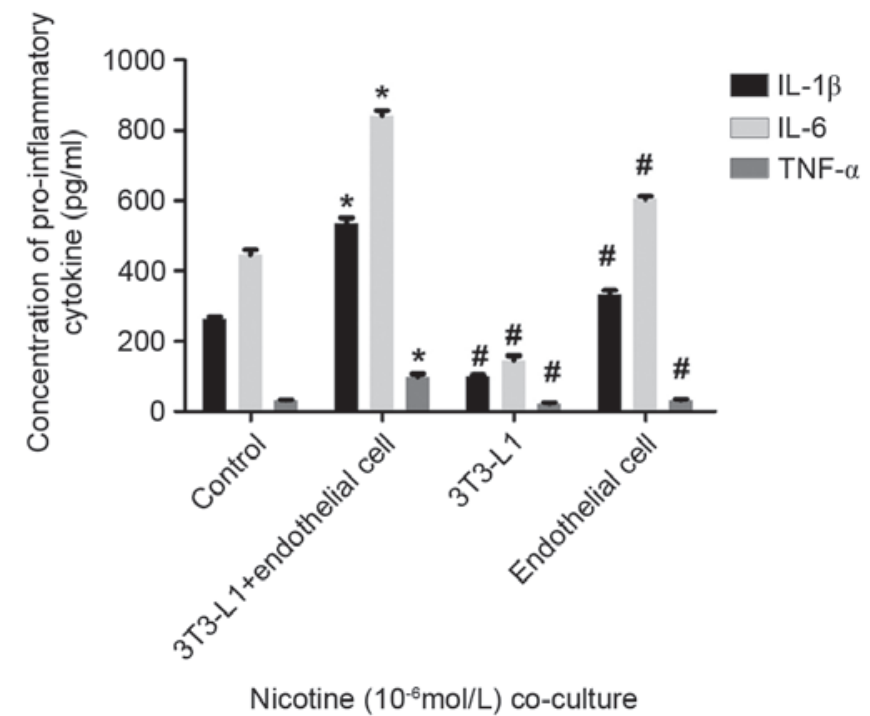

Figure 4. ELISA analysis showed that co-culture of mature adipocytes and human umbilical vein endothelial cells with nicotine at the concentrations $10^{-6} \mathrm{~mol} / 1$ resulted in a significant increases in levels of IL-6, IL-1 $\beta$ and TNF- $\alpha$ in media, compared with either cell cultured alone ${ }^{*} \mathrm{P}<0.05$, vs. control; ${ }^{*} \mathrm{P}<0.05$, vs. co-culture group ( $\mathrm{n}=5 /$ group). IL, interleukin; TNF- $\alpha$, tumor necrosis factor- $\alpha$.

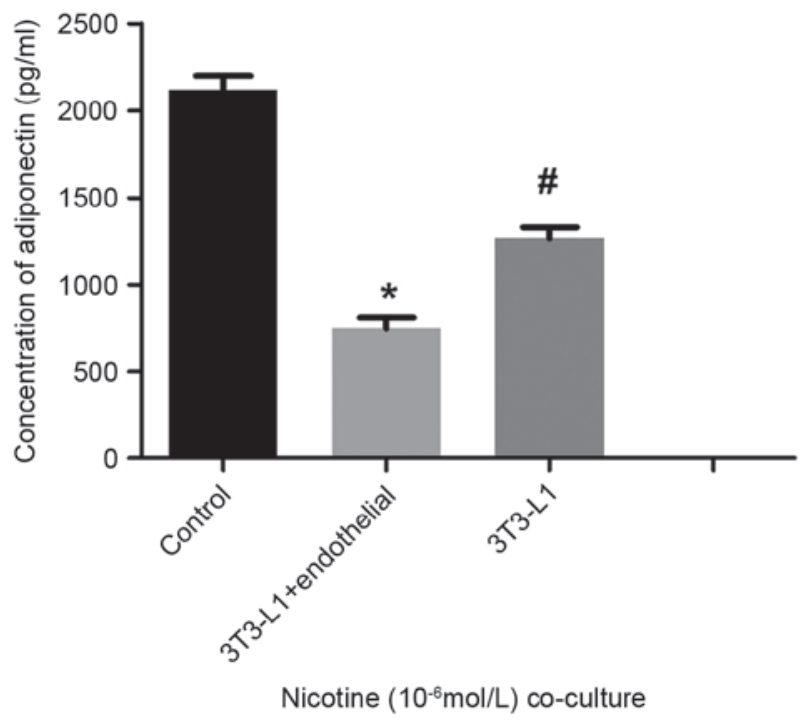

Figure 5. ELISA showed that adiponectin release into the media was significantly reduced by nicotine treatment at concentrations of $10^{-6} \mathrm{~mol} / \mathrm{l}$, compared with the control. " $\mathrm{P}<0.05$, vs. 3T3-L1 group; ${ }^{~} \mathrm{P}<0.05$, vs. control ( $\mathrm{n}=5 /$ group).

those of the mature adipocytes cultured alone ( $\mathrm{P}<0.05$; Fig. 5). Western blot analysis showed that nicotine induced the expression of VCAM-1, ICAM-1 and NF- $\kappa$ B p65 in the co-cultures of mature adipocytes and HUVECs. The levels of VCAM-1 and ICAM-1 in the co-cultured cells were significantly elevated, compared with those in the HUVECs cultured alone $(\mathrm{P}<0.01$; Fig. 6), and the co-culture group had significantly higher levels of NF- $\kappa \mathrm{B}$ p65, compared with the mature adipocytes or HUVECs cultured alone $(\mathrm{P}<0.01$; Fig. 7). These findings suggested that nicotine markedly upregulated the expression of inflammatory adipokines and adhesion molecules in
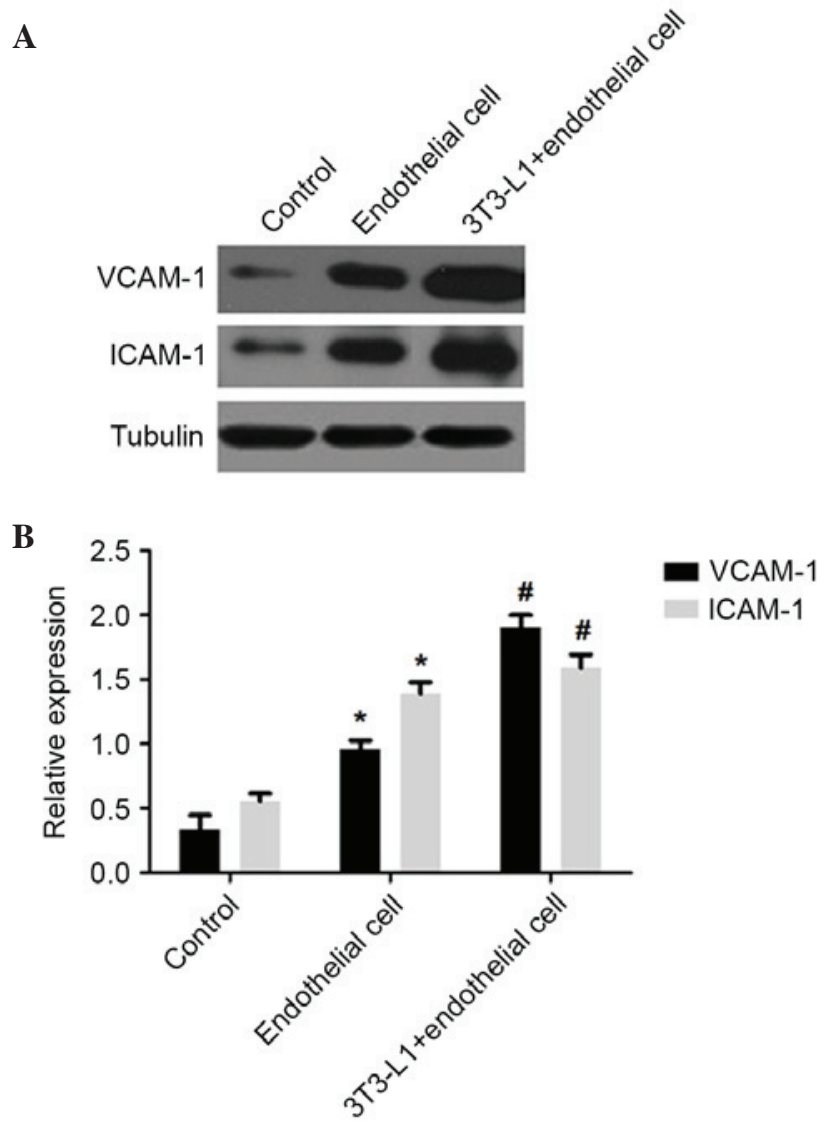

Figure 6. Western blot analysis of the expression of ICAM-1 and VCAM-1 in the control, co-culture and endothelial groups. (A) Western blots shown are representative samples of several experiments. (B) Quantification of the blot results. ${ }^{*} \mathrm{P}<0.01$, vs. control; ${ }^{\#} \mathrm{P}<0.01$, vs. endothelial group ( $\mathrm{n}=5 /$ group). ICAM-1, intercellular adhesion molecule 1; VCAM-1, vascular cell adhesion molecule-1.

co-cultured mature adipocytes and HUVECs. Additionally, the levels of adiponectin were significantly reduced in the co-cultures, compared with the levels in the mature adipocytes cultured alone.

\section{Discussion}

Epidemiological studies have shown that smoking is a major cause of atherosclerosis. Smoking can cause endothelial dysfunction through various mechanisms. PVAT can affect the structure and function of blood vessel walls by altering their endocrine and paracrine functions. The present study investigated nicotine stimulation of mature adipocytes, endothelial cells and a co-culture of these two cell types to investigate how adipocytes affect endocrine and paracrine functions to accelerate endothelial inflammation.

It has been shown that smoking habits are associated with adiponectin concentrations in men, in cultured 3T3-L1 adipocytes, nicotine reduces the secretion and expression of adiponectin (17). Gao et al (18) reported that nicotine can alter the composition and function of PVAT, resulting in increased blood pressure. Therefore, the present study investigated whether nicotine can cause vessel wall abnormalities as a consequence of the inflammatory response by altering the endocrine and paracrine functions of PVAT. Mature adipocytes were exposed 
A

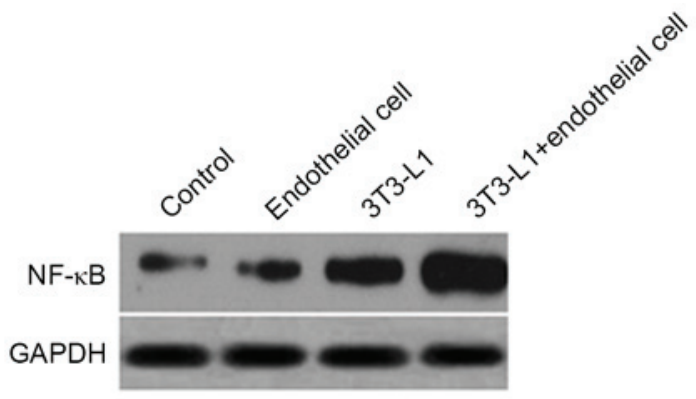

B

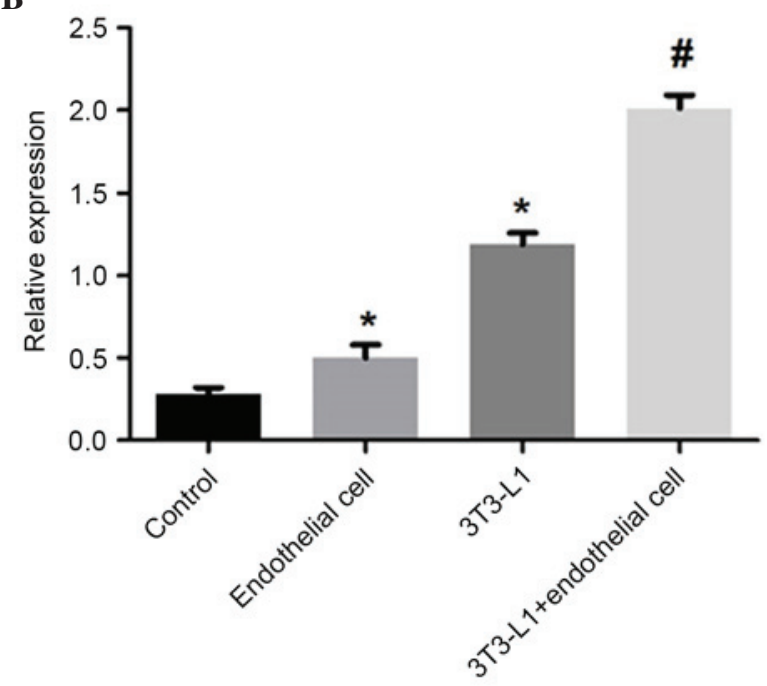

Figure 7. Western blot analysis of the expression levels of NF- $\kappa \mathrm{B}$ in the control, co-culture and endothelial groups. (A) Western blots shown are representative samples of several experiments. (B) Quantification of the western blot results ${ }^{*} \mathrm{P}<0.01$, vs. control; ${ }^{\#} \mathrm{P}<0.01$ vs. endothelial group and $3 \mathrm{~T} 3-\mathrm{L} 1$ group ( $\mathrm{n}=5 /$ group). $\mathrm{NF}-\kappa \mathrm{B}$, nuclear factor $-\kappa \mathrm{B}$.

to various concentrations of nicotine $\left(10^{-6}, 10^{-7}\right.$ and $\left.10^{-8} \mathrm{~mol} / \mathrm{l}\right)$ for $24 \mathrm{~h}$. It was found that the expression levels of IL-6 and IL-1 $\beta$ were significantly elevated in the nicotine-treated group. No significant differences were found in the levels of TNF- $\alpha$ following stimulation with $10^{-7}$ or $10^{-8} \mathrm{~mol} / \mathrm{l}$ nicotine, and only at a concentration of $10^{-6} \mathrm{~mol} / 1$ nicotine did the secretion of TNF- $\alpha$ increase significantly. Concentrations of plasma nicotine have been reported to approach $10^{-7} \mathrm{~mol} / \mathrm{l}$ in smokers (19). A previous study showed that HUVECs secrete TNF- $\alpha$ in response to nicotine at levels similar to those found in the serum following smoking $\left(10^{-6}-10^{-10} \mathrm{~mol} / \mathrm{l}\right)$, although the activity of TNF- $\alpha$ returned to baseline levels by $24 \mathrm{~h}$ (20). Following stimulation of adipocytes with nicotine for $24 \mathrm{~h}$ in the present study, the expression levels of TNF- $\alpha$ showed a similar trend to those of the HUVECs. Adiponectin is an anti-inflammatory cytokine, which can be secreted by adipocytes. It can inhibit inflammation by reducing the expression of various adhesion molecules by endothelial cells $(21,22)$. The findings of the present study showed that nicotine reduced the secreted levels of adiponectin in mature adipocytes, similar to findings reported in a previous study (19). Together, the findings of the present study suggested that nicotine at concentrations similar to those observed in the serum of smokers can lead to PVAT dysfunction, and cause the abnormal secretion of adiponectin and inflammatory adipokines. This suggested that PVAT may contribute to nicotine-induced endothelial inflammatory responses.
In this present study, it was also shown that secretion of the IL- 6 and IL-1 $\beta$ inflammatory adipokines by HUVECs was significantly increased following $24 \mathrm{~h}$ treatment with nicotine at concentrations of $10^{-6}-10^{-8} \mathrm{~mol} / \mathrm{l}$, however, no significant difference was found in the levels of TNF- $\alpha$. Previous studies have shown that nicotine can stimulate the secretion of TNF- $\alpha$ and IL-1 $\beta$ by macrophages, and promote the expression of endothelial cell adhesion factor (23). Overall, the results of the present study suggested that nicotine stimulation of endothelial cells caused increased secretion of inflammatory adipokines and increased endothelial inflammation.

The results described above showed that nicotine caused the abnormal secretion of adiponectin by adipocytes and that endothelial cells secreted inflammatory adipokines. To investigate the interactions between these cell types, adipocyte and HUVEC co-cultures were examined, which were exposed to $10^{-6} \mathrm{~mol} / 1 \mathrm{nicotine}$ for $24 \mathrm{~h}$. The co-culture led to upregulation in the secretion of IL- 6 , IL- $1 \beta$ and TNF- $\alpha$, however, the levels of adiponectin were decreased in the co-culture supernatants. Additionally, it was revealed that, in the co-culture group, the secretion of TNF- $\alpha$ was enhanced by stimulation with adipocyte-conditioned media. As the co-culture resulted in levels of adiponectin similar to those of the adipocytes cultured alone, further reductions in the secretion of adiponectin by adipocytes appeared to affect interactions with endothelial cells and the secretion of inflammatory adipokines. VCAM-1 and ICAM-1 can contribute to the recruitment of circulating inflammatory cells into vascular walls, which may explain the nicotine-induced infiltration of inflammatory cells. The findings of the present study suggested that the expression levels of ICAM-1 and VCAM-1 were upregulated in the co-culture system. A previous study also reported nicotine-induced expression of ICAM-1 and VCAM-1 by endothelial cells (24). Several factors may be involved in promoting inflammatory responses in endothelial cells, among which NF- $\mathrm{BB}$ is an important mediator of tissue inflammation. This transcription factor can drive several aspects of inflammation and induce the expression of several inflammatory mediators, including ICAM-1, VCAM-1 and various interleukins. A number of studies have indicated that cigarette smoking can cause tissue inflammation via the induction of $\mathrm{NF}-\kappa \mathrm{B}$, and nicotine has been reported to upregulate the expression of $\mathrm{NF}-\kappa \mathrm{B}$ in rat intravascular tissues (25-27). In the present study, nicotine markedly upregulated the expression of $\mathrm{NF}-\kappa \mathrm{B}$ in the co-cultured cells. In previously reported in vivo experiments, adiponectin has been found to modulate the inflammatory response of endothelial cells via cross-talk between the cyclic-AMP-protein kinase A and NF- $\mathrm{AB}$ signaling pathways (28). Therefore, the present study hypothesized that nicotine stimulated the co-cultured cells to activate the $\mathrm{NF}-\kappa \mathrm{B}$ signaling pathway by upregulating the expression of $\mathrm{NF}-\kappa \mathrm{B}$, which aggravated endothelial cells and exacerbated an inflammatory response. The results of the present study supported those of previous reports that adiponectin is an important mediator in the cross-talk between adipose tissue and the vasculature (29), therefore, adipocyte-endothelial cell interactions may be important in nicotine-induced endothelial inflammation.

In conclusion, the present study found that nicotine induced adipocyte dysfunction and caused the abnormal 
secretion of adiponectin and inflammatory adipokines, which further exacerbated endothelial inflammation. These findings provide evidence for an association between nicotine, PAVT and vascular damage, and offer insight into PVAT-targeted therapy for the protection of vasculature.

\section{Acknowledgements}

The present study was supported by the Peking Union Medical College Hospital Medical Research Funds (grant no. PUMCH 001).

\section{References}

1. Ambrose JA and Barua RS: The pathophysiology of cigarette smoking and cardiovascular disease: An update. J Am Coll Cardiol 43: 1731-1737, 2004.

2. Borgerding M and Klus H: Analysis of complex mixtures-cigarette smoke. Exp Toxicol Pathol 57 (Suppl 1): 43-73, 2005.

3. Lee J, Taneja V and Vassallo R: Cigarette smoking and inflammation: Cellular and molecular mechanisms. J Dent Res 91: 142-149, 2012.

4. Orosz Z, Csiszar A, Labinskyy N, Smith K, Kaminski PM, Ferdinandy P, Wolin MS, Rivera A and Ungvari Z: Cigarette smoke-induced proinflammatory alterations in the endothelial phenotype: Role of NAD (P)H oxidase activation. Am J Physiol Heart Circ Physiol 292: H130-H139, 2007.

5. Arnson Y, Shoenfeld Y and Amital H: Effects of tobacco smoke on immunity, inflammation and autoimmunity. J Autoimmun 34: J258-J265, 2010

6. Kuhlmann CR, Trümper JR, Tillmanns H, Alexander Schaefer $\mathrm{C}$ and Erdogan A: Nicotine inhibits large conductance $\mathrm{Ca}(2+)$-activated $\mathrm{K}(+)$ channels and the NO/-cGMP signaling pathway in cultured human endothelial cells. Scand Cardiovasc J 39: 348-352, 2005.

7. Glantz SA and Parmley WW: Passive and active smoking. A problem for adults. Circulation 94: 596-598, 1996.

8. Halberg N, Wernstedt-Asterholm I and Scherer PE: The adipocyte as an endocrine cell. Endocrinol Metab Clin North Am 37: 753-768, x-xi, 2008.

9. Lehr S, Hartwig S and Sell H: Adipokines: A treasure trove for the discovery of biomarkers for metabolic disorders. Proteomics Clin Appl 6: 91-101, 2012.

10. Kumada M, Kihara S, Sumitsuji S, Kawamoto T, Matsumoto S, Ouchi N, Arita Y, Okamoto Y, Shimomura I, Hiraoka H, et al: Association of hypoadiponectinemia with coronary artery disease in men. Arterioscler Thromb Vasc Biol 23: 85-89, 2003.

11. Adamczak M, Wiecek A, Funahashi T, Chudek J, Kokot F and Matsuzawa Y: Decreased plasma adiponectin concentration in patients with essential hypertension. Am J Hypertens 16: 72-75, 2003.

12. Ouchi N, Ohishi M, Kihara S, Funahashi T, Nakamura T, Nagaretani H, Kumada M, Ohashi K, Okamoto Y, Nishizawa $\mathrm{H}$, et al: Association of hypoadiponectinemia with impaired vasoreactivity. Hypertension 42: 231-234, 2003.

13. Van de Voorde J, Pauwels B, Boydens C and Decaluwé K: Adipocytokines in relation to cardiovascular disease. Metabolism 62: 1513-1521, 2013.
14. Suganami T, Tanimoto-Koyama K, Nishida J, Itoh M, Yuan X, Mizuarai S, Kotani H, Yamaoka S, Miyake K, Aoe S, et al: Role of the toll-like receptor 4/NF-kappaB pathway in saturated fatty acid-induced inflammatory changes in the interaction between adipocytes and macrophages. Arterioscler Thromb Vasc Biol 27: 84-91, 2007.

15. Yamashita A, Soga Y, Iwamoto Y, Yoshizawa S, Iwata H, Kokeguchi S, Takashiba $\mathrm{S}$ and Nishimura $\mathrm{F}$ : Macrophage-adipocyte interaction: Marked interleukin-6 production by lipopolysaccharide. Obesity (Silver Spring) 15: 2549-2552, 2007.

16. Lai N, Jayaraman A and Lee K: Enhanced proliferation of human umbilical vein endothelial cells and differentiation of 3T3-L1 adipocytes in coculture. Tissue Eng Part A 15: 1053-1061, 2009.

17. Iwashima Y, Katsuya T, Ishikawa K, Kida I, Ohishi M, Horio T, Ouchi N, Ohashi K, Kihara S, Funahashi T, et al: Association of hypoadiponectinemia with smoking habit in men. Hypertension 45: 1094-1100, 2005

18. Gao YJ, Holloway AC, Su LY, Takemori K, Lu C and Lee RM: Effects of fetal and neonatal exposure to nicotine on blood pressure and perivascular adipose tissue function in adult life. Eur J Pharmacol 590: 264-268, 2008.

19. Thielen A, Klus H and Müller L: Tobacco smoke: Unraveling a controversial subject. Exp Toxicol Pathol 60: 141-156, 2008.

20. Albaugh G, Kann B, Strande L, Vemulapalli P, Hewitt C and Alexander JB: Nicotine induces endothelial TNF-alpha expression, which mediates growth retardation in vitro. J Surg Res 99: 381-384, 2001.

21. Deng G, Long Y, Yu YR and Li MR: Adiponectin directly improves endothelial dysfunction in obese rats through the AMPK-eNOS pathway. Int J Obes (Lond) 34: 165-171, 2010.

22. Wang Y, Wang X, Lau WB, Yuan Y, Booth D, Li JJ, Scalia R, Preston K, Gao E, Koch W and Ma XL: Adiponectin inhibits tumor necrosis factor-alpha-induced vascular inflammatory response via caveolin-mediated ceramidase recruitment and activation. Circ Res 114: 792-805, 2014.

23. Wang Y, Wang L, Ai X, Zhao J, Hao X, Lu Y and Qiao Z: Nicotine could augment adhesion molecule expression in human endothelial cells through macrophages secreting TNF-alpha, IL-1beta. Int Immunopharmacol 4: 1675-1686, 2004.

24. Ueno H, Pradhan S, Schlessel D, Hirasawa H and Sumpio BE: Nicotine enhances human vascular endothelial cell expression of ICAM-1 and VCAM-1 via protein kinase C, p38 mitogen-activated protein kinase, NF-kappaB, and AP-1. Cardiovasc Toxicol 6: 39-50, 2006.

25. Gonçalves RB, Coletta RD, Silvério KG, Benevides L, Casati MZ, da Silva JS and Nociti FH Jr: Impact of smoking on inflammation: Overview of molecular mechanisms. Inflamm Res 60: 409-424, 2011.

26. Tsiara S, Elisaf M and Mikhailidis DP: Influence of smoking on predictors of vascular disease. Angiology 54: 507-530, 2003.

27. Yanbaeva DG, Dentener MA, Creutzberg EC, Wesseling G and Wouters EF: Systemic effects of smoking. Chest 131: 1557-1566, 2007.

28. Ouchi N, Kihara S, Arita Y, Okamoto Y, Maeda K, Kuriyama H, Hotta K, Nishida M, Takahashi M, Muraguchi M, et al: Adiponectin, an adipocyte-derived plasma protein, inhibits endothelial NF-kappaB signaling through a cAMP-dependent pathway. Circulation 102: 1296-1301, 2000.

29. Li FY, Cheng KK, Lam KS, Vanhoutte PM and Xu A: Cross-talk between adipose tissue and vasculature: Role of adiponectin. Acta Physiol (Oxf) 203: 167-180, 2011. 